\title{
Mechanical Characterization of Two Dental Restorative Materials after Acidic Challenge
}

\author{
Ana Coelho $1,2,3,4, *,+\left(\mathbb{D}\right.$, Anabela Paula ${ }^{1,2,3,4,+} \mathbb{C}$, Inês Amaro ${ }^{1}$, Carlos Miguel Marto ${ }^{1,2,3,4,5} \mathbb{D}$, Nuno Costa ${ }^{1}$, \\ José Saraiva ${ }^{1}$, Manuel Marques Ferreira ${ }^{2,3,4,6}$, Pedro Antunes ${ }^{7,8}$ and Eunice Carrilho ${ }^{1,2,3,4}$ (D) \\ 1 Institute of Integrated Clinical Practice, Faculty of Medicine, University of Coimbra, \\ 3000-075 Coimbra, Portugal; anabelabppaula@sapo.pt (A.P.); ines.amaros@hotmail.com (I.A.); \\ cmiguel.marto@uc.pt (C.M.M.); nunomgscosta@gmail.com (N.C.); ze-93@hotmail.com (J.S.); \\ eunicecarrilho@gmail.com (E.C.) \\ 2 Area of Environment, Genetics and Oncobiology (CIMAGO), Institute for Clinical and Biomedical \\ Research (iCBR), Faculty of Medicine, University of Coimbra, 3000-548 Coimbra, Portugal; \\ m.mferreira@gmail.com \\ 3 Clinical Academic Center of Coimbra (CACC), 3004-561 Coimbra, Portugal \\ 4 Centre for Innovative Biomedicine and Biotechnology (CIBB), University of Coimbra, \\ 3000-548 Coimbra, Portugal \\ 5 Institute of Experimental Pathology, Faculty of Medicine, University of Coimbra, 3000-548 Coimbra, Portugal \\ 6 Institute of Endodontics, Faculty of Medicine, University of Coimbra, 3000-075 Coimbra, Portugal \\ 7 Department of Mechanical Engineering, Centre for Mechanical Engineering, Materials and \\ Processes (CEMMPRE), University of Coimbra, 3030-788 Coimbra, Portugal; pedro.antunes@dm.uc.pt \\ 8 Itecons-Institute of Research and Technological Development in Construction, Energy, Environment and \\ Sustainability, Rua Pedro Hispano, 3030-289 Coimbra, Portugal \\ * Correspondence: anasofiacoelho@gmail.com \\ + These authors contribute equally.
}

Citation: Coelho, A.; Paula, A Amaro, I.; Marto, C.M.; Costa, N.; Saraiva, J.; Ferreira, M.M.; Antunes, P.; Carrilho, E. Mechanical Characterization of Two Dental Restorative Materials after Acidic Challenge. J. Compos. Sci. 2021, 5, 31 https://doi.org/10.3390/jcs5010031

Received: 22 December 2020 Accepted: 14 January 2021 Published: 16 January 2021

Publisher's Note: MDPI stays neutral with regard to jurisdictional clai$\mathrm{ms}$ in published maps and institutional affiliations.

Copyright: (C) 2021 by the authors. Licensee MDPI, Basel, Switzerland. This article is an open access article distributed under the terms and conditions of the Creative Commons Attribution (CC BY) license (https:// creativecommons.org/licenses/by/ $4.0 /)$.

\begin{abstract}
The aim of this study was to determine the effect of acidic beverages on the mechanical characteristics of a nanofilled composite resin and of a glass ionomer. Thirty specimens of each restorative material were produced and were evaluated at three different time points: before immersion (T0), after a 7 day immersion (T1) and after a 14 day immersion (T2) in water, beer and a soft drink. The studied parameters were microhardness and surface roughness. At T2, composite resin and glass ionomer specimens immersed in water, beer and the soft drink showed a statistically significant decrease in microhardness compared to T0 results. The surface roughness of composite resin specimens decreased between T0 and T1/T2 after immersion in beer and soft drink. A statistically significant increase was found between the roughness of glass ionomer specimens immersed in each one of the beverages at T0 and T1/T2. It is essential that clinicians are aware not only of available restorative materials, its characteristics and best handling techniques but also of the importance of performing an adequate assessment of patients' dietary habits, thus making it possible to offer patients quality treatments with a predictable prognosis and longevity.
\end{abstract}

Keywords: composite resin; glass ionomer; mechanical properties; acidic beverages

\section{Introduction}

Direct restorative approaches are currently one of the main treatment options in restoring esthetics and function of the teeth. There are several materials available for this purpose for either permanent or temporary restorative procedures, namely composite or glass ionomer-based materials [1].

The use of a composite resin in clinical dental practice makes it possible to carry out an accessible permanent dental rehabilitation, with good esthetic, mechanical and chemical performance. On the other hand, glass ionomer-based materials are often used in temporary procedures. In these situations, these materials should be able to offer a quality 
rehabilitation during the time period between appointments, which generally includes the removal of dental caries lesions and the definitive restoration [2-5].

The viability, longevity and good clinical performance of restorations will always be the main goals of these kinds of treatments. However, the degradation of restorative materials may occur due to intrinsic (e.g., eating disorders) and extrinsic (e.g., diet, medication, oral hygiene and smoking) etiological phenomena as well as due to normal wear and exposure to the oral cavity environment [4-7]. Therefore, not all restorative materials guarantee functional longevity of rehabilitations, presenting with a clear need to control these restorations in order to prevent failure [4,5].

Behavior of dental composites and other restorative materials in a normal oral environment is well studied by several papers that reproduced normal oral conditions by means of immersion of samples in artificial saliva, and all reported changes in the surface of restorative materials, namely a decrease in microhardness and an increase in surface roughness $[1,8,9]$. Although this is well documented, some patients present more defying oral situations, for example when there is a higher consumption of acidic beverages, making it necessary to also develop further research on its impact on restorative materials. In fact, the consumption of acidic drinks and consequent erosive phenomena is increasing worldwide, presenting as side effects an increase in tooth wear and a significant increase in the materials' degradation and risk of restoration failure [10,11].

In order to determine the effect of acidic beverages on the mechanical characteristics of restorative materials, the present study aimed to assess a nanofilled composite resin and a glass ionomer's surface microhardness, roughness and weight gain from the absorption after immersion in three acidic drinks: water, beer and a soft drink.

\section{Materials and Methods}

For this study, a nanofilled composite resin-Filtek Supreme XTE ${ }^{\mathrm{TM}}$ (3M ESPETM, St. Paul, MN, USA) — and a glass ionomer-based material—Ketac ionomer-basedcap ${ }^{\mathrm{TM}}$ (3M $\mathrm{ESPE}^{\mathrm{TM}}$, St. Paul, MN, USA) - were used. The characteristics of the selected materials are presented in Table 1.

Table 1. Characteristics of restorative materials used in the present study.

\begin{tabular}{|c|c|c|}
\hline Material & $\begin{array}{c}\text { Filtek Supreme XTE } \\
\text { (3M ESPE } \\
\text { TM }, \text { St.Paul, MN, USA) }\end{array}$ & $\begin{array}{c}\text { Ketac Universal Aplicap } \\
\left(3 \mathrm{M} \mathrm{ESPE}^{\mathrm{TM}} \text {, St. Paul, MN, USA) }\right.\end{array}$ \\
\hline Composition & $\begin{array}{c}\text { Non-agglomerated/non- } \\
\text { aggregated } 20 \mathrm{~nm} \text { silica filler, } \\
\text { non-agglomerated/non- } \\
\text { aggregated } 4-11 \mathrm{~nm} \text { zirconia filler, } \\
\text { aggregated zirconia/silica cluster } \\
\text { filler, UDMA, TEGDMA, bis-EMA, } \\
\text { bis-GMA }\end{array}$ & $\begin{array}{l}\text { Powder: ZnO Glass } \\
\text { Liquid: water, copolymer of acrylic } \\
\text { acid-maleic acid, tartaric acid }\end{array}$ \\
\hline Lot no. & N805469 & 629441 \\
\hline
\end{tabular}

Sixty specimens - thirty of each restorative material, composite resin and glass ionomerwere produced using a silicone mold $(12 \times 6 \times 4 \mathrm{~mm}-$ length $\times$ width $\times$ thickness $)$ especially made for this purpose.

The mold was filled manually, in one increment, with each one of the restorative materials and covered with a glass slab. The specimens were then photopolymerized using an LED polymerizing unit (Bluephase ${ }^{\circledR}$, Ivoclar Vivadent AG, FL-9494 Schaan, Liechtenstein) with a light intensity of $1200 \mathrm{~mW} / \mathrm{cm}^{2} \pm 10 \%$ for $40 \mathrm{~s}$. The curing light intensity was verified with a radiometer Bluephase ${ }^{\circledR}$ meter (Ivoclar Vivadent AG, FL-9494 Schaan, Liechtenstein).

The upper and lower sides of all specimens were polished using a polishing machineLaboPol- $5^{\circledR}$ (Struers ApS, Ballerup, Denmark)—with several abrasive discs and using them in a decreasing order of abrasiveness (Buehler, Lake Bluff, IL, USA), thus performing 
a gradual and controlled surface smoothing (P320; P600; P2500) and reducing surface roughness.

Afterwards, the specimens were randomly divided into 6 groups (G1-G6). Each group had 10 specimens, numbered from 1 to 10 , allowing their individual identification.

The specimens were stored in sterile $100 \mathrm{~mL}$ containers, where three beverages were added as an immersion medium: G1 and G2-bottled water (Caldas de Penacova ${ }^{\circledR}$, Penacova, Portugal); G3 and G4-beer (Super Bock ${ }^{\circledR}$, Unicer, Portugal) and G5 and G6-soft drink (Coca-Cola ${ }^{\circledR}$, The Coca-Cola Company, Madrid, Spain). The beverage's characteristics are summarized in Table 2.

Table 2. Beverages used for immersion of composite resin and glass ionomer specimens.

\begin{tabular}{|c|c|c|c|c|}
\hline $\begin{array}{l}\text { Acidic } \\
\text { Beverage }\end{array}$ & Brand & Composition & Lot No. & $\mathrm{pH}$ \\
\hline Water & $\begin{array}{l}\text { Caldas de } \\
\text { Penacova }^{\circledR} \\
\text { (Penacova, } \\
\text { Portugal) }\end{array}$ & 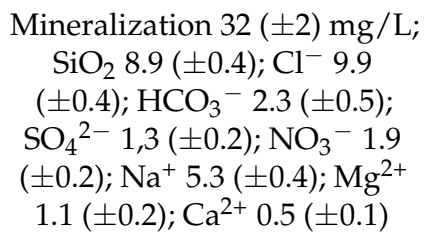 & $\begin{array}{l}\text { LD153171 } 213 \\
\text { LC159171 } 030\end{array}$ & 5.3 \\
\hline Soft drink & $\begin{array}{l}\text { Coca-Cola }{ }^{\circledR} \\
\text { (The Coca-Cola } \\
\text { Company, } \\
\text { Spain) }\end{array}$ & $\begin{array}{c}\text { Carbonated water, sugar, } \\
\text { colour (caramel E150d), } \\
\text { natural flavourings } \\
\text { (including caffeine), acidulant } \\
\text { (E-338), carbon dioxide (E290) }\end{array}$ & $\begin{array}{l}\text { L9E55:12 } \\
\text { L3C08:51 }\end{array}$ & 1.78 \\
\hline Beer & $\begin{array}{l}\text { Super Bock }^{\circledR} \\
\text { (Unicer, } \\
\text { Portugal) }\end{array}$ & $\begin{array}{l}\text { Water, barley malt, unmalted } \\
\text { cereals (corn and barley), } \\
\text { hops (5.2\% vol.) }\end{array}$ & $\begin{array}{l}\text { L2513572 } \\
\text { L3144291 }\end{array}$ & 4.2 \\
\hline
\end{tabular}

All specimens were evaluated at three different time points: before immersion in the beverages (T0), after a 7 day immersion (T1) and after a 14 day immersion (T2).

The volume of each drink used in each container was enough to fully immerse all specimens, estimated at $40 \mathrm{~mL}$. All groups were stored in an oven during the experimental time period, at $37^{\circ} \mathrm{C}$. The immersion media were renewed on the 7th day of immersion (T1).

\subsection{Specimens Weight}

A $150 \mathrm{~mm}$ digital caliper (Mitutoyo, Tokyo, Japan) was used to measure each specimen, with an error of $0.01 \mathrm{~mm}$, and each one was further weighed on a high-precision digital weighing microbalance (Mettler, Toledo, Switzerland), with the readings recorded at the nearest $0.00001 \mathrm{~g}$. All specimens were weighed before and after immersion in all three solutions at every time point. Prior to every weight measurement, all samples were gently dried with absorbent paper and left undisturbed for $5 \mathrm{~min}$ to allow stabilization.

\subsection{Surface Microhardness Analysis}

Microhardness measurements were evaluated on the upper side of each specimen, with the purpose of eliminating the influence of the indentations resulting from the Vickers test method. The Vickers test was performed using Struers Duramin-2 (Struers A/S, Ballerup, Denmark) testing equipment, according to the standard DIN EN ISO 6507 part 1-3, ASTM E-384-99; Knoop: ISO 4545 (0.2 kgf-(1.962 N)—HV0.2, 40 s).

Indentation measurements were performed according to the Standard Test Method for Microindentation Hardness of Materials (ASTM WK27978, 2010). Five measurements were performed on each sample, evenly distributed along the surface, each one of them being perpendicular to the previous one, minimizing the influence of directionality. 


\subsection{Surface Roughness Analysis}

Surface roughness was evaluated on one of the specimens' surfaces. These measurements were performed by means of a surface roughness evaluation machine, Mitutoyo Surftest-Series SJ-500/P 178 (Mitutoyo, Tokyo, Japan), according to the standard DIN EN ISSO 4288 [12]. This instrument allows the two-dimensional tracking of a surface.

The specimens were positioned on a metallic support. The recommended extension for surface measurement was $4 \mathrm{~mm}$ according to the standard. The evaluated profile is the surrounding profile of the actual acquired surface. The traced profile consists of deviations in shape, roughness and undulation components. The parameters are usually defined over the length of the sample.

Therefore, an estimate of each average parameter is automatically calculated, taking the arithmetic mean of the parameter estimates of all individual sample lengths for roughness profile parameters for each specimen. Regarding curves and related parameters, the basis for calculating parameter values is the length of the evaluation.

The monitored roughness parameters used for surface roughness analysis were $\mathrm{Ra}$ (average surface roughness), $\mathrm{Rz}$ (mean roughness depth), $\mathrm{Rq}$ (root mean square roughness), and Rsk (roughness skewness).

The average surface roughness, $R_{a}$, is the arithmetic average of the absolute values of the roughness profile ordinates. Mean roughness depth, $R_{z}$, is defined as the average distance between the highest peak and lowest valley within a sampling length. $R_{\mathrm{q}}$ represents the root mean square value of ordinate values. The skewness parameter $\left(R_{s k}\right)$ is a measure of the symmetry of the amplitude density function. This last parameter considers the profile's symmetry regarding the midline, which characterizes the asymmetry of height distribution concerning Gaussian distribution. A surface profile where the total valley area is less than the total peak area will have a positive $R_{\text {sk }}$ and in the opposite case a negative $R_{s k}$. The $R_{s k}$ value may be used to distinguish differently shaped surfaces with the same $R_{a}$ value. Moreover, $R_{s k}$ is strongly influenced by isolated peaks and valleys, which reduces its practical importance.

Ten measurements were performed on each specimen, distributed along the width of the surface under analysis and perpendicular to the previous one to minimize the influence of directionality.

The statistical analysis was performed by means of the IBM ${ }^{\circledR}$ SPSS $^{\circledR}$ software v.26.0 (IBM Corporation, Amrnonk, New York, NY, USA). The normality of the variables was assessed according to the Kolmogorov-Smirnov test. Student $t$-tests and the three-way ANOVA test were used. Multiple comparisons were done by Scheffé statistical. The level of significance assumed was $5 \%$.

\section{Results}

\subsection{Specimens Weight}

Regarding the weight of the specimens, all weight measurements remained without alterations from T0 to T2 (Table 3). No statistically significant differences were found between groups in all three of the evaluation times $(p>0.05)$.

Table 3. Weight measurements (T0/T1/T2).

\begin{tabular}{ccc}
\hline Material & Glass Ionomer & Composite Resin \\
\hline Water & $0.54 \pm 0.02$ & $0.45 \pm 0.03$ \\
\hline Soft drink & $0.52 \pm 0.02$ & $0.48 \pm 0.04$ \\
\hline Beer & $0.54 \pm 0.02$ & $0.43 \pm 0.03$ \\
\hline
\end{tabular}

\subsection{Surface Microhardness Analysis}

The initial surface microhardness (T0) was significantly higher $(p<0.001)$ in the glass ionomer specimens when compared with the composite resin specimens $(p<0.001)$. 
Regarding the initial surface microhardness of the composite resin specimens, no statistically significant differences were identified between groups. However, at T1, composite resin specimens immersed in water, beer and soft drink showed a decrease in the initial microhardness. The only decrease in microhardness found to be statistically significant $(p=0.020)$ was that of specimens immersed in beer. A statistically significant difference was also identified regarding the microhardness of resin specimens immersed in water and those immersed in beer and in the soft drink $(p=0.001)$. No statistically significant differences were found between resin specimens immersed in beer and those immersed in the soft drink. At T2, composite resin specimens immersed in water, beer and the soft drink showed a statistically significant decrease in microhardness compared to T0 results. A statistically significant difference was found between specimens immersed in water and in beer $(p=0.006)$ and in the soft drink $(p<0.001)$.

Regarding the initial microhardness of the glass ionomer specimens, no statistically significant differences were found between groups. Glass ionomer specimens immersed in water, beer and soft drink for 7 days (T1) showed a decrease in the initial microhardness. Differences with statistical significance were observed regarding the decrease in microhardness of samples immersed in beer $(p<0.001)$ and in the soft drink $(p<0.001)$. A statistically significant difference was also identified between the microhardness of glass ionomer specimens immersed in water and in beer $(p<0.001)$ and in the soft drink $(p=0.001)$. No statistically significant differences were found between glass ionomer specimens immersed in beer and those immersed in the soft drink. The decrease in microhardness observed between $\mathrm{T} 0$ and $\mathrm{T} 2$ and between $\mathrm{T} 1$ and $\mathrm{T} 2$ was statistically significant for all beverages $(p<0.001)$. At T2, a statistically significant difference was also found between specimens immersed in water and in beer $(p<0.001)$ and in the soft drink $(p<0.001)$, as well as between specimens immersed in beer and in the soft drink $(p<0.001)$.

Results for the microhardness of glass ionomer and composite resin specimens are presented in Table 4.

Table 4. Results regarding microhardness of glass ionomer and composite resin specimens.

\begin{tabular}{ccccccccccc}
\hline & \multicolumn{3}{c}{ Water } & & \multicolumn{3}{c}{ Beer } & \multicolumn{3}{c}{ Soft Drink } \\
\hline Time & T0 & T1 & T2 & T0 & T1 & T2 & T0 & T1 & T2 \\
\hline Glass & $119.93 \pm$ & $104.82 \pm$ & $91.54 \pm$ & $118.46 \pm$ & $86.13 \pm$ & $67.43 \pm$ & $118.42 \pm$ & $82.91 \pm$ & $55.66 \pm$ \\
ionomer & 11.0 & 4.24 & 6.35 & 9.74 & 4.23 & 3.69 & 9.76 & 4.72 & 3.94 \\
\hline Composite & $89.42 \pm$ & $81.16 \pm$ & $69.30 \pm$ & $91.32 \pm$ & $75.60 \pm$ & $64.67 \pm$ & $87.54 \pm$ & $74.67 \pm$ & $62.64 \pm$ \\
resin & 8.00 & 2.67 & 5.61 & 12.53 & 4.12 & 4.99 & 6.22 & 4.35 & 4.32 \\
\hline
\end{tabular}

\subsection{Surface Roughness Analysis}

Given the measurement error resulting from deep cracks and a large surface texture irregularity, the $R_{z}$ parameter was considered to be invalid for glass ionomer specimens evaluation.

Results for the different roughness parameters evaluated in glass ionomer and composite resin specimens are presented in Tables 5 and 6, respectively.

The surface roughness of composite resin specimens decreased between T0 and T1 after immersion in beer $(p=0.003)$ and soft drink $(p=0.035)$. Between T0 and T2, statistically significant differences were found between surface roughness results regarding resin specimens immersed in beer $(p=0.003)$ and in the soft drink $(p=0.029)$. No significant differences were found concerning composite resin specimens immersed in water in any of the three experimental time periods.

Statistically significant differences were found between the roughness of glass ionomer specimens immersed in each one of the beverages at T0 and T1 $(p<0.001)$, as well as between T0 and T2 $(p<0.001)$.

No statistically significant differences were found between roughness results at T1 and $\mathrm{T} 2$ for any of the materials after immersion in each one of the beverages. 
Table 5. Results regarding roughness of glass ionomer specimens.

\begin{tabular}{ccccccccccc}
\hline Parameter & \multicolumn{3}{c}{ Water } & & \multicolumn{3}{c}{ Beer } & \multicolumn{3}{c}{ Soft Drink } \\
\hline Time & T0 & T1 & T2 & T0 & T1 & T2 & T0 & T1 & T2 \\
\hline \multirow{2}{*}{$\mathrm{R}_{\mathrm{a}}$} & $0.32 \pm$ & $0.36 \pm$ & $0.36 \pm$ & $0.30 \pm$ & $0.41 \pm$ & $0.41 \pm$ & $0.32 \pm$ & $0.53 \pm$ & $0.54 \pm$ \\
& 0.11 & 0.18 & 0.10 & 0.09 & 0.23 & 0.19 & 0.10 & 0.27 & 0.17 \\
\hline \multirow{2}{*}{$\mathrm{R}_{\mathrm{q}}$} & $0.71 \pm$ & $0.87 \pm$ & $0.87 \pm$ & $0.55 \pm$ & $0.94 \pm$ & $0.94 \pm$ & $0.71 \pm$ & $1.14 \pm$ & $1.14 \pm$ \\
& 0.37 & 0.50 & 0.33 & 0.18 & 0.72 & 0.63 & 0.24 & 0.78 & 0.50 \\
\hline \multirow{2}{*}{$\mathrm{R}_{\mathrm{sk}}$} & $-5.83 \pm$ & $-6.65 \pm$ & $-6.55 \pm$ & $-5.06 \pm$ & $-5.01 \pm$ & $-5.01 \pm$ & $-7.29 \pm$ & $-3.72 \pm$ & $-3.73 \pm$ \\
& 2.27 & 2.42 & 2.02 & 3.11 & 3.09 & 2.51 & 2.26 & 2.47 & 2.07 \\
\hline
\end{tabular}

Table 6. Results regarding roughness of composite resin specimens.

\begin{tabular}{ccccccccccc}
\hline Parameter & \multicolumn{3}{c}{ Water } & \multicolumn{3}{c}{ Beer } & \multicolumn{3}{c}{ Soft Drink } \\
\hline Time & T0 & T1 & T2 & T0 & T1 & T2 & T0 & T1 & T2 \\
\hline \multirow{2}{*}{$\mathrm{R}_{\mathrm{a}}$} & $0.29 \pm$ & $0.28 \pm$ & $0.28 \pm$ & $0.27 \pm$ & $0.23 \pm$ & $0.23 \pm$ & $0.26 \pm$ & $0.23 \pm$ & $0.23 \pm$ \\
& 0.07 & 0.08 & 0.03 & 0.07 & 0.06 & 0.02 & 0.09 & 0.09 & 0.05 \\
\hline \multirow{2}{*}{$\mathrm{R}_{\mathrm{z}}$} & $2.66 \pm$ & $2.37 \pm$ & $2.37 \pm$ & $1.93 \pm$ & $2.09 \pm$ & $2.09 \pm$ & $2.36 \pm$ & $2.32 \pm$ & $2.32 \pm$ \\
& 0.71 & 0.41 & 0.71 & 1.29 & 0.52 & 0.37 & 0.70 & 0.86 & 0.60 \\
\hline \multirow{2}{*}{$\mathrm{R}_{\mathrm{q}}$} & $0.38 \pm$ & $0.38 \pm$ & $0.38 \pm$ & $0.38 \pm$ & $0.38 \pm$ & $0.31 \pm$ & $0.38 \pm$ & $0.35 \pm$ & $0.35 \pm$ \\
& 0.01 & 0.01 & 0.05 & 0.03 & 0.05 & 0.04 & 0.01 & 0.12 & 0.08 \\
\hline \multirow{2}{*}{$\mathrm{R}_{\mathrm{sk}}$} & $-1.35 \pm$ & $-1.15 \pm$ & $-1.15 \pm$ & $-1.52 \pm$ & $-0.58 \pm$ & $-0.60 \pm$ & $-1.48 \pm$ & $-1.63 \pm$ & $-1.68 \pm$ \\
& 1.04 & 0.55 & 0.87 & 1.15 & 1.24 & 0.80 & 1.71 & 1.44 \\
\hline
\end{tabular}

\section{Discussion}

The success of dental rehabilitation using restorative materials such as composite resin and glass ionomer is mostly related to the longevity of the restorative procedures, thus being essential for the careful identification and evaluation of all parameters that may jeopardize it [13].

The oral cavity is a complex environment, where the influence of different intrinsic and extrinsic factors, can compromise the esthetics, function and longevity of different restorative materials. The influence of dietary habits, namely of beverages with erosive potential, whose consumption has increased over the last few decades, is already recognized in the literature, which makes the study of its effects on different dental materials of uttermost importance [14-18].

In the present study, three drinks with a high consumption rate-bottled mineral water, beer and soft drink-were selected for the experimental protocol. After fourteen days, it was possible to identify significant differences in microhardness and roughness of glass ionomer and composite resin specimens immersed in the different beverages. The specimens immersed in beer and soft drink, the ones with the lowest $\mathrm{pH}$ values, presented with the most changes, which is in line with the results from a similar study [19].

Regarding microhardness results, they are in line with several studies that analyze the effect of alcoholic and carbonated beverages on different restorative materials [4,20-23]. Karaman et al. [22] reported a decrease in microhardness of Filtek Supreme XTE ${ }^{\mathrm{TM}}$ after a 15-day challenge with Coke $^{\circledR}$, as well as Gupta et al. [23], who reported a decrease in microhardness of different restorative materials (composites, compomers and glass ionomers) after a $10 \mathrm{~min} /$ day immersion in Coke ${ }^{\circledR}$ for 56 days. Poggio et al. [24] also immersed four different composites in Coke ${ }^{\circledR}$ and orange juice for 1 and 7 days, and a significant decrease in microhardness was also registered for all the groups. Silva et al. [4] tested the effect of three different alcoholic beverages on three composite resin materials and also reported a decrease in microhardness after a 30 day immersion in beer. On the other hand, Ilday et al. [19] tested the effect of three different acidic beverages, on surface characteristics of four different composite resin materials and did not find significant 
changes in the composites' surface microhardness. However, the authors only evaluated the effects for over a 7-day time period.

Although most studies that use water as an immersion medium report that the microhardness of the evaluated restorative materials does not change [6,25-28], the bottled water used in this study presents a low $\mathrm{pH}$ value (5.3), which may justify the results. The decrease in surface microhardness observed after immersion of the specimens (glass ionomer and composite resin) in water, beer and soft drink may be associated with hydrolytic degradation caused by these beverages. The water absorption causes the spaces between the linear chains of the polymers to expand, causing the loss of the chemical bond between the fillers and the matrix. The nanoparticles move from the outer surface, causing a decrease in microhardness $[4,20,27,28]$.

The composition of the evaluated materials (monomers, fillers and coupling agents) is also of significant importance regarding the results. Filtek Supreme $\mathrm{XTE}^{\mathrm{TM}}$, for example, presents in its organic matrix the BisEMA monomer, which has a high molecular weight and is resistant to degradation due to the removal of $\mathrm{OH}$ group terminals, which are susceptible to absorption and solubility. However, monomers such as UDMA, TEGDMA and Bis-GMA are very susceptible to absorption and solubility when in contact with alcohol, which may cause softening and degradation of the organic matrix [29,30]. There is, however, a clear need for more clinical trials to evaluate these parameters, since it is described that the salivary film that adheres to materials may act as a protective barrier [31].

Regarding roughness, most existing studies only evaluate the $R_{a}$ parameter, which makes it impossible to accurately assess the surface of the materials as well as to compare results $[32,33]$. Even though $R_{a}$ is the most commonly used roughness parameter to describe surface texture, it is not capable of making a distinction between peaks and valleys nor does it qualitatively evaluate its form or consider unusual ones. Therefore, it is necessary to include other parameters in the analysis to improve the faulty roughness evaluation when using $R_{a}$ alone. $R_{z}$ and $R_{s k}$ parameters characterize the depth between peaks and valleys. A surface with predominantly deep valleys has a greater susceptibility to infiltration in its cracks and indentations, which is of great importance when evaluating materials used in oral rehabilitation [32,34].

The increase in surface roughness, observed in glass ionomer specimens, can determine the increase in bacterial infiltration and adhesion, allowing for a fast microbial colonization. The subsequent oral biofilm maturation is associated with a greater susceptibility to periodontal disease and dental caries. Furthermore, materials with a higher surface roughness are more susceptible to color changes, compromising the esthetics of the restoration [35-38]. Filtek Supreme $\mathrm{XTE}^{\mathrm{TM}}$, a nanofilled composite resin, presents with a particle size varying from 4 to $20 \mathrm{~nm}$. Ketac Aplicap Universal ${ }^{\mathrm{TM}}$ results from the mixture of a powder and a liquid, making it more susceptible to infiltration and to an increase in surface roughness $[34,39]$. These characteristics may explain the different profilometric changes resulting from the immersion of the specimens.

Although this study allows a better understanding of the effects of acidic beverages on dental materials, it has some limitations, for example, the number of specimens per group could have been higher to promote more accurate results. In addition, the specimens were immersed only in undiluted solutions, which do not replicate the oral environment since, in the oral cavity, saliva dilutes every liquid. Placement of the specimens in artificial saliva after immersion in the acidic beverages could have been performed to simulate a clinical condition. Thermocycling could also have been carried out to mimic an aging environment. Further clinical studies should also be conducted in order to confirm the effect of these beverages in the restorative materials.

The results are in line with those of other studies, which evaluated different beverages with a low $\mathrm{pH}$ value, proving the importance of this characteristic in the integrity of different restorative materials. The composition of such materials is also an important factor to consider in the severity of changes caused by acidic solutions, but the influence of 
other factors, such as the presence of alcohol in beverages' composition and oral hygiene, must also be considered $[4,20-22,27,40]$.

\title{
5. Conclusions
}

From the experimental protocol, it was possible to observe changes in microhardness and surface roughness of a composite resin and a glass ionomer after 14 days of immersion in water, beer and a soft drink. It is essential that clinicians are aware not only of available restorative materials, their characteristics and best handling techniques, but also of the importance of performing an adequate assessment of patients' dietary habits, thus making it possible to offer patients quality treatments with a predictable prognosis and longevity.

\begin{abstract}
Author Contributions: Data curation, A.C., A.P., I.A., N.C.; formal analysis, A.C., A.P., I.A. and P.A.; investigation, A.C., A.P., N.C., C.M.M., M.M.F., P.A., E.C.; methodology, P.A., M.M.F., E.C.; project administration, M.M.F., P.A., E.C.; resources, A.C., A.P., M.M.F., P.A., E.C.; software, A.C, A.P., I.A., C.M.M., P.A.; supervision, A.C., A.P., P.A., E.C.; validation, A.C., A.P., P.A.; visualization, A.P., M.M.F., E.C.; writing—original draft, A.C., A.P., I.A., J.S., N.C.; writing-review and editing, A.P., C.M.M., M.M.F., P.A., E.C. All authors have read and agreed to the published version of the manuscript.
\end{abstract}

Funding: This research received no external funding.

Conflicts of Interest: The authors declare no conflict of interest.

\section{References}

1. Yilmaz, E.; Sadeler, R. Effect of artificial aging environment and time on mechanical properties of composite materials. J. Dent. Res. Rev. 2018, 5, 111. [CrossRef]

2. Ferracane, J.L. Current trends in dental composites. Crit. Rev. Oral Biol. Med. 1995, 6, 302-318. [CrossRef] [PubMed]

3. Spahl, W.; Budzikiewicz, H.; Geurtsen, W. Determination of leachable components from four commercial dental composites by gas and liquid chromatography/mass spectrometry. J. Dent. 1998, 26, 137-145. [CrossRef]

4. Da Silva, M.A.B.; Vitti, R.P.; Sinhoreti, M.A.; Consani, R.L.; Silva-Junior, J.G.; Tonholo, J. Effect of alcoholic beverages on surface roughness and microhardness of dental composites. Dent. Mater. J. 2016, 35, 621-626. [CrossRef]

5. Toledano, M.; Osorio, R.; Osorio, E.; Fuentes, V.; Prati, C.; Garcia-Godoy, F. Sorption and solubility of resin-based restorative dental materials. J. Dent. 2003, 31, 43-50. [CrossRef]

6. Festuccia, M.S.; Garcia Lda, F.; Cruvinel, D.R.; Pires-De-Souza Fde, C. Color stability, surface roughness and microhardness of composites submitted to mouthrinsing action. J. Appl. Oral Sci. 2012, 20, 200-205. [CrossRef]

7. Briso, A.L.; Caruzo, L.P.; Guedes, A.P.; Catelan, A.; dos Santos, P.H. In vitro evaluation of surface roughness and microhardness of restorative materials submitted to erosive challenges. Oper. Dent. 2011, 36, 397-402. [CrossRef]

8. Venturini, D.; Cenci, M.S.; Demarco, F.F.; Camacho, G.B.; Powers, J.M. Effect of polishing techniques and time on surface roughness, hardness and microleakage of resin composite restorations. Oper. Dent. 2006, 31, 11-17. [CrossRef]

9. Voltarelli, F.R.; Santos-Daroz, C.B.; Alves, M.C.; Cavalcanti, A.N.; Marchi, G.M. Effect of chemical degradation followed by toothbrushing on the surface roughness of restorative composites. J. Appl. Oral Sci. 2010, 18, 585-590. [CrossRef] [PubMed]

10. Isaksson, H.; Birkhed, D.; Wendt, L.K.; Alm, A.; Nilsson, M.; Koch, G. Prevalence of dental erosion and association with lifestyle factors in Swedish 20-year olds. Acta Odontol. Scand. 2014, 72, 448-457. [CrossRef] [PubMed]

11. Tedesco, T.K.; Calvo, A.F.B.; Yoshioka, L.; Fukushima, K.A.; Cesar, P.F.; Raggio, D.P. Does Acid Challenge Affect the Properties and Bond Stability of Restorative Materials on Primary Teeth? J. Adhes. Dent. 2018, 20, 223-231. [CrossRef] [PubMed]

12. ISO 4287:1997 Geometrical Product Specifications (GPS)—Surface Texture: Profile Method—Terms, Definitions and Surface Texture Parameters; International Standard Organization, Technical Commitee: Geneva, Switzerland, 2008; ASME B2046.2001.

13. Al-Thobity, A.M.; Gad, M.M.; Farooq, I.; Alshahrani, A.S.; Al-Dulaijan, Y.A. Acid Effects on the Physical Properties of Different CAD/CAM Ceramic Materials: An in Vitro Analysis. J. Prosthodont. 2020. [CrossRef] [PubMed]

14. Cheng, R.; Yang, H.; Shao, M.Y.; Hu, T.; Zhou, X.D. Dental erosion and severe tooth decay related to soft drinks: A case report and literature review. J. Zhejiang Univ. Sci. B 2009, 10, 395-399. [CrossRef]

15. Wongkhantee, S.; Patanapiradej, V.; Maneenut, C.; Tantbirojn, D. Effect of acidic food and drinks on surface hardness of enamel, dentine, and tooth-coloured filling materials. J. Dent. 2006, 34, 214-220. [CrossRef] [PubMed]

16. Santos, M.J.; Rego, H.M.; Mukhopadhyay, A.; El Najjar, M.; Santos, G.C., Jr. Effect of artificial aging on the surface roughness and microhardness of resin-based materials. Gen. Dent. 2016, 64, e13-e17. [PubMed]

17. De Moraes, R.R.; Marimon, J.L.; Schneider, L.F.; Sinhoreti, M.A.; Correr-Sobrinho, L.; Bueno, M. Effects of 6 months of aging in water on hardness and surface roughness of two microhybrid dental composites. J. Prosthodont. 2008, 17, 323-326. [CrossRef] [PubMed]

18. Noble, W.H.; Donovan, T.E.; Geissberger, M. Sports drinks and dental erosion. J. Calif. Dent. Assoc. 2011, 39, $233-238$. 
19. İlday, N.; Bayindir, Y.Z.; Erdem, V. Effect of three different acidic beverages on surface characteristics of composite resin restorative materials. Mater. Res. Innov. 2013, 14, 385-391. [CrossRef]

20. Fatima, N.; Hussain, M. Effect of two different commonly available energy drinks on surface micro hardness of tooth color restorative materials. J. Res. Dent. 2014, 2, 269-276. [CrossRef]

21. Rajavardhan, K.; Sankar, A.; Kumar, M.; Kumar, K.; Pranitha, K.; Kishore, K. Erosive potential of cola and orange fruit juice on tooth colored restorative materials. Ann. Med. Health Sci. Res. 2014, 4, 208-212. [CrossRef]

22. Karaman, E.; Tuncer, D.; Firat, E.; Ozdemir, O.S.; Karahan, S. Influence of different staining beverages on color stability, surface roughness and microhardness of silorane and methacrylate-based composite resins. J. Contemp. Dent. Pract. 2014, 15, 319-325. [CrossRef] [PubMed]

23. Gupta, R.; Madan, M.; Dua, P.; Saini, S.; Mangla, R.; Kainthla, T.; Dupper, A. Comparative Evaluation of Microhardness by Common Drinks on Esthetic Restorative Materials and Enamel: An in vitro Study. Int. J. Clin. Pediatr. Dent. 2018, 11, 155-160. [CrossRef] [PubMed]

24. Poggio, C.; Viola, M.; Mirando, M.; Chiesa, M.; Beltrami, R.; Colombo, M. Microhardness of different esthetic restorative materials: Evaluation and comparison after exposure to acidic drink. Dent. Res. J. 2018, 15, 166-172. [CrossRef]

25. Soderholm, K.J.; Zigan, M.; Ragan, M.; Fischlschweiger, W.; Bergman, M. Hydrolytic degradation of dental composites. J. Dent. Res. 1984, 63, 1248-1254. [CrossRef] [PubMed]

26. Alshali, R.Z.; Salim, N.A.; Satterthwaite, J.D.; Silikas, N. Long-term sorption and solubility of bulk-fill and conventional resin-composites in water and artificial saliva. J. Dent. 2015, 43, 1511-1518. [CrossRef] [PubMed]

27. Bamise, C.; Mejabi, M.; Esan, T. Short Term Sorption Effect on three Esthetic Dental Filling Materials in Various Media. Adv. Res. 2015, 5, 1-9. [CrossRef]

28. Braden, M. Water absorption characteristics of dental microfine composite filling materials. Biomaterials 1984, 5, 373-375. [CrossRef]

29. Carvalho, F.G.; Sampaio, C.S.; Fucio, S.B.; Carlo, H.L.; Correr-Sobrinho, L.; Puppin-Rontani, R.M. Effect of chemical and mechanical degradation on surface roughness of three glass ionomers and a nanofilled resin composite. Oper. Dent. 2012, 37, 509-517. [CrossRef]

30. Ferracane, J.L. Hygroscopic and hydrolytic effects in dental polymer networks. Dent. Mater. 2006, 22, 211-222. [CrossRef]

31. Badra, V.V.; Faraoni, J.J.; Ramos, R.P.; Palma-Dibb, R.G. Influence of different beverages on the microhardness and surface roughness of resin composites. Oper. Dent. 2005, 30, 213-219.

32. Perez Cdos, R.; Hirata, R.J.; Da Silva, A.H.; Sampaio, E.M.; De Miranda, M.S. Effect of a glaze/composite sealant on the 3-D surface roughness of esthetic restorative materials. Oper. Dent. 2009, 34, 674-680. [CrossRef] [PubMed]

33. Marigo, L.; Rizzi, M.; La Torre, G.; Rumi, G. 3-D surface profile analysis: Different finishing methods for resin composites. Oper. Dent. 2001, 26, 562-568. [PubMed]

34. Kakaboura, A.; Fragouli, M.; Rahiotis, C.; Silikas, N. Evaluation of surface characteristics of dental composites using profilometry, scanning electron, atomic force microscopy and gloss-meter. J. Mater. Sci Mater. Med. 2007, 18, 155-163. [CrossRef] [PubMed]

35. Abu-Bakr, N.; Han, L.; Okamoto, A.; Iwaku, M. Changes in the mechanical properties and surface texture of compomer immersed in various media. J. Prosthet. Dent. 2000, 84, 444-452. [CrossRef]

36. Ellakuria, J.; Triana, R.; Minguez, N.; Soler, I.; Ibaseta, G.; Maza, J.; Garcia-Godoy, F. Effect of one-year water storage on the surface microhardness of resin-modified versus conventional glass-ionomer cements. Dent. Mater. 2003, 19, 286-290. [CrossRef]

37. Ibrahim, H. Effects of Various Beverages on Hardness, Roughness, and Solubility of Esthetic Restorative Materials. J. Esthet. Restor. Dent. 2011, 23, 315-322. [CrossRef]

38. Topaloglu-Ak, A.; Cogulu, D.; Ersin, N.K.; Sen, B.H. Microhardness and surface roughness of glass ionomer cements after APF and TiF4 applications. J. Clin. Pediatr. Dent. 2012, 37, 45-51. [CrossRef]

39. Karda, B.; Jindal, R.; Mahajan, S.; Sandhu, S.; Sharma, S.; Kaur, R. To Analyse the Erosive Potential of Commercially Available Drinks on Dental Enamel and Various Tooth Coloured Restorative Materials-An In-vitro Study. J. Clin. Diagn. Res. 2016, 10, ZC117. [CrossRef]

40. Ertas, E.; Guler, A.U.; Yucel, A.C.; Koprulu, H.; Guler, E. Color stability of resin composites after immersion in different drinks. Dent. Mater. J. 2006, 25, 371-376. [CrossRef] 